\title{
Association between depressive symptoms, use of antidepressant medication and the metabolic syndrome: the Maine-Syracuse Study
}

Georgina E. Crichton ${ }^{1 *}$, Merrill F. Elias ${ }^{2,3}$ and Michael A. Robbins ${ }^{2,3}$

\begin{abstract}
Background: Both depression and the metabolic syndrome (MetS) are two major public health issues. The aim of this study was to examine associations between depressive symptoms, the use of antidepressant medications, and the prevalence of MetS.

Methods: Cross-sectional analyses were undertaken on 970 participants from the Maine-Syracuse Study. Depressive symptoms were measured using two self-reported depression scales, the Center for Epidemiological Studies Depression Scale (CES-D), and the Zung self-rating depression scale. Antidepressant medication use was also self-reported. MetS was defined according to the recent harmonized criteria.

Results: The risk of MetS were approximately 79 and $86 \%$ higher for those in the highest quartile for the CESD and the Zung (CES-D: $\mathrm{OR}=1.79, p=0.003$; Zung: $\mathrm{OR}=1.71, p=0.006$ ), compared to those in the lowest quartile. With adjustment for socio-demographic variables, lifestyle factors and C-reactive protein (CRP), risk was attenuated, but remained statistically significant for the CES-D. In those who reported using antidepressant medication, the odds of having MetS were over 2-fold higher ( $\mathrm{OR}=2.22, p<0.001$, fully adjusted model), compared to those who did not use antidepressants. Both measures of depressed mood were also associated with low high density-lipoprotein (HDL) cholesterol levels. Antidepressant use was associated with elevated fasting plasma glucose concentrations, hypertension, and low HDL-cholesterol.
\end{abstract}

Conclusion: Depressive symptoms and the use of antidepressant medications are associated with the prevalence of MetS, and with some of the individual components of the syndrome.

Keywords: Depressed mood, Antidepressants, Metabolic syndrome

\section{Background}

The clustering together of abdominal obesity, hypertension, dyslipidemia and insulin resistance is referred to as the metabolic syndrome (MetS). A syndrome can be regarded as "a clustering of factors that occur together more often than by chance alone and for which the cause is often uncertain" ([1], p.1641). The worldwide prevalence of MetS is increasing, in part attributable to

\footnotetext{
* Correspondence: georgina.crichton@unisa.edu.au

${ }^{1}$ Alliance for Research in Exercise, Nutrition and Activity (ARENA), Sansom Institute for Health Research, University of South Australia, GPO Box 2471, Adelaide, South Australia 5001, Australia

Full list of author information is available at the end of the article
}

the rise in obesity [1]. While there is not a single known cause for MetS, a number of non-modifiable factors including age, genetics, ethnicity and sex, influence the syndrome's prevalence [2]. Having MetS is associated with a 1.7 -fold increase in the risk for cardiovascular disease (CVD) [3]. For non-diabetics with MetS, the likelihood of developing future type 2 diabetes increases seven-fold [4], further augmenting CVD risk. The presence of MetS may also be a future predictor of mortality $[5,6]$. Research is needed to generate public health measures to combat MetS and develop interventions for at-risk individuals.

Like MetS, depression is associated with an increased risk of diabetes [7] and CVD [8]. Depression is one of 
the most common psychological illnesses affecting adults in the United States (US), with over 15 million adults having had at least one major depressive episode in 2013 [9]. With both MetS and depression being recognised as major public health challenges, attention has been drawn to associations between the two.

A recent systematic review and meta-analysis investigated the current evidence for an association between depression and MetS from 29 cross-sectional and 11 prospective studies [10], and concluded that a bidirectional association exists. While a growing amount of literature suggests that depressive symptoms and more severe depressive episodes are associated with MetS [10-13], some inconsistent results have been reported [14, 15], and the direction of this association remains uncertain.

Fewer studies have examined any association between antidepressant use and MetS. A recent study suggests that antidepressants are a stronger predictor of type 2 diabetes than are depressive symptoms [16]. As antidepressants may directly effect components of MetS, in particular, weight gain [17-19], it is important to consider antidepressant use in relation to the syndrome. The PPP-Botnia Study (PPP = prevalence, prediction, and prevention of diabetes), a large Finnish population-based study, recently examined associations between depressive symptoms, use of antidepressant medication and MetS [20]. In this study the odds for having MetS increased over $10 \%$ for each standard deviation increase in depressive symptoms, and users of antidepressant medication had more than $50 \%$ increased odds for having MetS. More studies such as this one are needed to extend what is currently known about these relations. Few, if any, studies have used more than a single depression scale, and it is important to know if similar results are obtained for two different mesures of depressed mood.

Therefore, the present study also reports associations between depressive symptoms using two different selfreport scales one prominent in the epidemiology literature (Zung) and one prominent in the psychology literature (CES-D), antidepressant use, and MetS prevalence, and also tests relations with the individual components of MetS, in a US community-based sample. Further, we examine if any potential associations vary according to apolipoprotein $\varepsilon 4$ (APOE $\varepsilon 4$ ) status. It is hypothesized that there will be a positive association between self-reported depressive symptoms and MetS prevalence, and that those on antidepressant medication will have a higher likelihood of having MetS.

\section{Methods}

\section{Participants}

Data were obtained from participants of the MaineSyracuse Longitudinal Study (MSLS), which commenced in 1975 and was designed to measure blood pressure and cognitive performance [21, 22] and expanded at
Wave 6 to examine other cardiovascular risk factors. The MSLS employs a time-lagged-longitudinal-cohort design with new subjects featuring an initial wave of data collection and then new subjects recruited into the study every five years with the same recruitment procedures as employed for every wave.

Sample characteristics at Wave 6 (Table 1) differed in two ways from those at the initial wave of testing, approximately 25 years earlier. Subjects were older (Wave 1 mean age $=48.0 \pm 16.0$ years), there were fewer women (Wave 1 proportion $=56 \%$ ), and mean blood pressures were lower due to the need to treat subjects once hypertension was detected (Wave 1: mean systolic $=137 \pm$ $28 \mathrm{mmHg}$, mean diastolic $=82 \pm 18 \mathrm{mmHg}$ ). In this context, it is important to note that our analysis was crosssectional at Wave 6 and our goal was not to duplicate sample charcteristics from a study begun years ealier. No comparison between our MetS data or our covariates at Wave 6 with Wave 1 are possible because data pertienet to MetS were all collected for the first time at Wave 6.

The only recruitment exclusions (common to all waves) were institutionalization, diagnosed psychiatric disorder and alcoholism. Participants for the present study were those returning for the sixth (2001-2006) study wave. Details of initial study recruitment have been previously described [21-24]. Beginning with 1049 individuals, participants for the present study were excluded for the following reasons: missing cardiometabolic, depression or medication data $(n=36)$, acute stroke $(n=28)$, probable dementia $(n=8)$, undertaking dialysis treatment $(n=5)$, inability to read English $(n=1)$, and prior alcohol abuse $(n=1)$. The final sample with complete wave 6 data comprised 970 individuals, aged 23 to 98 years.

Stroke, defined as a focal neurological deficit of acute onset persisting more than $24 \mathrm{~h}$, was based on self-report and was confirmed by a record review indicating a diagnosis of acute stroke. Clinical diagnoses of dementia were determined from cognitive data and medical records using the National Institute of Neurological and Communicative Diseases and Stroke/Alzheimer's Disease and Related Disorders Association (NINCDS-ADRDA) criteria [25] and confirmed using the ICD-10 Guidelines [26].

\section{Ethics, consent and permissions}

This study was conducted according to the guidelines established by the Declaration of Helsinki and all procedures were approved by the University of Maine Institutional Review Board. Written informed consent was obtained from all subjects.

\section{Procedure}

\section{Metabolic syndrome}

Metabolic syndrome was defined according to the International Diabetes Federation and the American Heart 
Table 1 Demographic, cardiovascular and health variables for Maine-Syracuse Longitudinal Study ( $N=970)$ participants according to metabolic syndrome status

\begin{tabular}{|c|c|c|c|c|c|}
\hline \multirow{3}{*}{ Variable } & \multicolumn{4}{|l|}{ MetS } & \multirow{3}{*}{$P$-value } \\
\hline & \multicolumn{2}{|l|}{$\begin{array}{l}\text { No } \\
n=539\end{array}$} & \multicolumn{2}{|l|}{$\begin{array}{l}\text { Yes } \\
n=431\end{array}$} & \\
\hline & $\mathrm{M}$ or $\%$ & SD & M or $\%$ & SD & \\
\hline Age, years & 60.7 & 13.4 & 63.7 & 11.9 & $<0.001$ \\
\hline Gender & & & & & 0.1 \\
\hline Males & 38.8 & & 43.9 & & \\
\hline Females & 61.2 & & 56.1 & & \\
\hline Education, years & 15.1 & 2.6 & 14.1 & 2.7 & $<0.001$ \\
\hline Race & & & & & 0.019 \\
\hline Caucasian & 94.2 & & 90.3 & & \\
\hline African American & 5.8 & & 9.7 & & \\
\hline Smoking, no cigarettes/day & 1.0 & 4.2 & 1.8 & 6.4 & 0.027 \\
\hline $\mathrm{BMl}, \mathrm{kg} / \mathrm{m}^{2}$ & 27.1 & 4.5 & 32.1 & 6.2 & $<0.001$ \\
\hline $\begin{array}{l}\text { Physical activity, } \\
\text { MET mins/day }\end{array}$ & 1517 & 1803 & 880 & 1370 & $<0.001$ \\
\hline Total cholesterol, mg/dL & 204.8 & 37.1 & 197.0 & 42.2 & 0.002 \\
\hline HDL cholesterol, mg/dL & 59.2 & 5.2 & 46.7 & 12.4 & $<0.001$ \\
\hline LDL cholesterol, mg/dL & 125.8 & 32.0 & 114.5 & 33.8 & $<0.001$ \\
\hline Systolic BP, mmHg & 124.8 & 21.0 & 138.5 & 19.9 & $<0.001$ \\
\hline Diastolic BP, mmHg & 68.6 & 9.9 & 72.8 & 9.7 & $<0.001$ \\
\hline Fasting blood glucose, mg/dL & 90.6 & 15.4 & 109.5 & 35.9 & $<0.001$ \\
\hline Waist circumference, cm & 88.8 & 12.4 & 103.6 & 14.0 & $<0.001$ \\
\hline CRP, mg/L & 0.36 & 0.43 & 0.52 & 0.53 & $<0.001$ \\
\hline Triglycerides, mg/dL & 101.9 & 47.0 & 192.4 & 143.3 & $<0.001$ \\
\hline Alcohol intake, g/week & 41.6 & 74.6 & 29.2 & 62.3 & 0.006 \\
\hline Depressed mood, CES-D score ${ }^{b}$ & 6.8 & 6.4 & 8.5 & 7.3 & $<0.001$ \\
\hline Depressed mood, Zung score ${ }^{b}$ & 41.1 & 8.5 & 43.8 & 10.1 & $<0.001$ \\
\hline$\%$ using antidepressants & 8.3 & & 15.1 & & 0.001 \\
\hline$\%$ Obese $\left(\mathrm{BMI} \geq 30 \mathrm{~kg} / \mathrm{m}^{2}\right)$ & 20.8 & & 61.4 & & $<0.001$ \\
\hline$\%$ Diabetes mellitus ${ }^{c}$ & 2.0 & & 25.5 & & $<0.001$ \\
\hline$\%$ Hypertension $^{d}$ & 40.8 & & 87.5 & & $<0.001$ \\
\hline$\% C V D^{e}$ & 8.0 & & 22.0 & & $<0.001$ \\
\hline$\%$ APOE ع4 & 26.9 & & 27.0 & & 0.9 \\
\hline
\end{tabular}

$A P O E \varepsilon 4$ apolipoprotein $\varepsilon 4, B M I$ body mass index, $B P$ blood pressure, CES-D Center for Epidemiologic Studies Depression Scale, CRP C-reactive protein, CVD cardiovascular disease, MetS metabolic syndrome, MET metabolic equivalent, MSLS Maine-Syracuse Longitudinal Study

ancludes moderate and intense self-reported physical activity

${ }^{\mathrm{b}}$ Higher scores indicates greater number of depressive symptoms

'Fasting plasma glucose $\geq 126 \mathrm{mg} / \mathrm{dL}$ or taking anti-diabetic medication

${ }^{\mathrm{d}}$ Systolic $\mathrm{BP} \geq 140 \mathrm{mmHg}$ and/or diastolic $\mathrm{BP} \geq 90 \mathrm{mmHg}$ or taking anti-hypertensive medication

eIncludes myocardial infarction, coronary artery disease, heart failure, angina pectoris, transient ischemic attack

Association/National Heart, Lung, and Blood Institute, which requires 3 of 5 risk factors to be present [1] namely abdominal obesity (WHO waist circumference cut-offs for Caucasian population: men $\geq 94 \mathrm{~cm}$, women $\geq 80 \mathrm{~cm}$ ), elevated blood pressure (systolic: $\geq 130$ and/or diastolic $\geq 85 \mathrm{mmHg}$ ), elevated fasting plasma glucose $(\geq 5.6 \mathrm{mmol} / \mathrm{L}$ or $\geq 100 \mathrm{mg} / \mathrm{dL})$, elevated triglycerides $(\geq 1.7 \mathrm{mmol} / \mathrm{L}$ or $\geq 150 \mathrm{mg} / \mathrm{dL})$, reduced high density lipoprotein (HDL) cholesterol $(<1.0 \mathrm{mmol} / \mathrm{L}$ or $<40 \mathrm{mg} /$ $\mathrm{dL}$ for males; $<1.3 \mathrm{mmol} / \mathrm{L}$ or $<50 \mathrm{mg} / \mathrm{dL}$ for females).

Standard assay methods were employed [21] to obtain fasting plasma glucose $(\mathrm{mg} / \mathrm{dL})$, total cholesterol $(\mathrm{TC}$, $\mathrm{mg} / \mathrm{dL}$ ), low-density lipoprotein cholesterol (LDL, mg/ $\mathrm{dL}$ ), high-density lipoprotein cholesterol (HDL, $\mathrm{mg} / \mathrm{dL}$ ), triglycerides $(\mathrm{mg} / \mathrm{dL})$ and C-reactive protein (CRP, $\mathrm{mg} /$ L), following an overnight fast. Waist circumference (in centimetres) was taken over light clothing, using a nonextendable measuring tape, at the level of the iliac crest. Automated blood pressure measures (GE DINAMAP 100DPC-120XEN, GE Healthcare) were taken five times each in reclining, sitting and standing after a supine rest for $15 \mathrm{~min}$, and averaged over the 15 assessments to obtain mean systolic blood pressure (BP) and diastolic BP.

\section{Depressed mood}

Depressive symptoms were assessed using the Center for Epidemiological Studies Depression Scale (CES-D) [27] and the Zung self-rating depression scale [28]. The CESD consists of 20 statements about feelings (e.g., happy, fearful, depressed) and behaviors (e.g., crying, eating, sleeping) and participants are required to indicate how often they have felt or behaved in these ways within the past week on a 4-point scale (from none of the time (0), to all of the time (3)). Total scores range from 0 to 60 , with higher scores indicating a greater number of symptoms. A total score of 16 or higher is considered to indicate depressed mood.

The Zung self-rating depression scale [28] consists of 20 statements about feelings and symptoms of depression, such as sleep and appetite. Each statement is rated by the participant on a 4-point scale, ranging from 1) a little of the time, to 4) most of the time. Total scores were multipled by 1.25 to given a final scale ranging from 25 to 100, with higher scores indicating more depressive symptoms. A score of 62.5 or higher is considered to indicate depressed mood. Both scales have demonstrated reliability and validity [29-32]. The use of antidepressant medication was self-reported in the $\mathrm{Nu}$ trition and Health Questionnaire [33, 34].

\section{Other health and demographic variables}

Demographic, socioeconomic and lifestyle characteristics were obtained from the Nutrition and Health Questionnaire [33, 34]. Education level (years) was obtained through self-report and ranged from 4 to 20 years. Physical activity was measured with the Nurses' Health Study Activity Questionnaire, a validated measure of time spent 
engaging in various physical activities [35]. MET-hours per week for each activity were calculated and summed to give total MET-minutes per week [36]. Smoking status was based on self-report from the Nutrition and Health Questionnaire [37].

Diabetes mellitus was defined as having a fasting plasma glucose $\geq 126 \mathrm{mg} / \mathrm{dl}$ or taking anti-diabetic medication, and CVD was considered present if any of the following were present: myocardial infarction, coronary artery disease, heart failure, angina pectoris, or transient ischemic attack.

\section{Statistical analyses}

Participant demographics, health and psychological variables were compared according to MetS status (yes/no). Independent samples $t$-tests were used for continuous variables and Chi-square for categorical variables for the analyses involving demographic variables.

Logistic regression analyses were used to determine whether depressive symptoms (CES-D and Zung) and antidepressant use (yes/no) were associated with MetS. After determining that the relation between depressive symptoms and MetS was not linear, the analysis was performed using scores from each quartile. The three highest quartiles were compared with the lowest quartile (reference group). Odds ratios (OR) and $95 \%$ confidence intervals (CI) were computed. Potential confounding variables were selected if they correlated with both depressive symptoms and MetS, or were of theoretical or clinical importance. The following covariance models were employed to adjust for confounding in the primary analysis:

Model 1: Basic: age (years) + gender + education (years) + ethnicity;

Model 2: Basic + smoking (cigarettes/day), physical activity (MET hours/week), CRP (mg/L).

In addition, the odds of having any of the individual MetS components were determined according to depressive symptoms (CES-D and Zung) and antidepressant use in the MSLS. The same two covariate sets were used.

\section{Sensitivity analyses}

Analyses examining relations between depressive symptoms and MetS were performed again, excluding participants reporting use of antidepressants. Further, the same analyses examining potential associations between depressive symptoms and MetS, and between antidepressant use and MetS, were performed after excluding individuals with existing type 2 diabetes or CVD.

To test if any of the potential associations differed for men and women, or according to age, interaction terms (sex*depressive symptoms, sex*antidepressant medication use; age"depressive symptoms, age*antidepressant medication use) were calculated and added to the basic models.

As other studies have shown that the influence of depressive symptoms may be greater for individuals with the apolipoprotein E4 (APOE ع4) allele compared to those without the allele, for example, on cognitive functioning [38], we also tested the possibility that the APOE $\varepsilon 4$ allele modifies the relation between depressed mood and MetS, i.e. interaction terms (APOE $\varepsilon 4^{*}$ depressive symptoms, APOE $\varepsilon 4$ *antidepressant medication use) were calculated and added to the basic models.

Due to the established effect of depressive symptoms on neuropathologial changes in brain regions, the analyses were repeated with a comprehensive measure of global cognitive function (the MSLS global cognitive composite score) added to the extended model. Finally, as antidepressant medication may impact upon body weight, in a final step, weight was added to the extended model examining the association between antidepressant use and MetS.

\section{Results \\ Demographic and preliminary findings}

The demographic, cardiovascular and health variables for MSLS $(N=970)$ participants according to MetS status are shown in Table 1 . Those with MetS were slightly older, smoked more, had a higher mean BMI and reported less physical activity. They had significantly lower HDL-, LDL- and total cholesterol than those without MetS; and, as would be expected, they had significantly higher systolic BP, diastolic BP, fasting blood glucose, waist circumference, and triglycerides. Those with MetS reported significantly more depressive symptoms, as measured by both scales, than those without MetS. In total, 110 participants (33 males and 77 females; $11.3 \%$ of the sample), reported using antidepressant medication. Of those taking antidepressants, a significantly higher proportion had MetS than did not. Depressive symptoms were associated with use of antidepressant medication. Those with scores in the highest quartile of depressed mood had significantly higher odds of using antidepressants compared to those with scores in the lowest quartile (basic models: Zung: OR: 4.67, $95 \% \mathrm{CI}$ : 2.40-9.08, $P<0.001$; CES-D: OR: 3.46, 95 \% CI: $1.86-$ 6.46, $P<0.001$ ) (data not shown). The CES-D and Zung were highly correlated with each other (Pearsons $r=0.61$, $P<0.001)$.

\section{Main findings}

\section{Depressive symptoms and MetS}

Those with the highest quartile of scores on the CES-D had a $79 \%$ higher risk of having MetS (basic model, OR: 1.79, $P<0.01$ ), and those with the highest quartile of scores on the Zung had a $71 \%$ higher risk of having 
MetS (basic model, OR: 1.71, $P<0.01$ ), compared to those with scores in the lowest quartile (Table 2). Those with scores in the second and third quartiles did not differ significantly $(P>0.05)$ from those with the lowest scores in terms of MetS risk, for either of the depressed mood measures.

For the extended model (addition of risk factor covariates), relations between depressed mood and MetS seen with the basic mode (age, education, gener and ethnicity) remained significant for the CES-D, with some attenuation of risk (see Table 2). Those with scores in the highest qurtile on the CES-D had a significantly higher risk for MetS, compared to those with scores in the lowest quartile.

\section{Antidepressant medication use and MetS}

Those on antidepressants ( $n=110,11.3 \%$ of the sample) had slightly over a two-fold increase in relative risk for MetS, compared to those not taking antidepressants (extended model: $\mathrm{OR}=2.22, P<0.001)($ Table 2$)$.

Table 2 Odds of having metabolic syndrome according to presence of depressive symptoms and use of antidepressant medications in the Maine-Syracuse Longitudinal Study

\begin{tabular}{|c|c|c|c|c|c|}
\hline \multirow{2}{*}{$\begin{array}{l}\text { Depressive symptoms/ } \\
\text { medication use }\end{array}$} & \multirow{2}{*}{$\begin{array}{l}\text { Covariate } \\
\text { set }^{a}\end{array}$} & \multirow{2}{*}{$\begin{array}{l}\text { Quartile } \\
\text { of scores }^{b}\end{array}$} & \multicolumn{3}{|c|}{ MetS } \\
\hline & & & $\overline{O R}$ & $95 \% \mathrm{Cl}$ & $P$-value \\
\hline \multirow[t]{8}{*}{ CES-D score } & \multirow[t]{4}{*}{ Basic } & Q4 & 1.79 & $1.22,2.62$ & 0.003 \\
\hline & & Q3 & 1.35 & $0.93,1.97$ & 0.1 \\
\hline & & Q2 & 1.05 & $0.72,1.54$ & 0.8 \\
\hline & & Q1 & 1.00 & & \\
\hline & \multirow[t]{4}{*}{ Extended } & Q4 & 1.50 & $1.00,2.24$ & 0.049 \\
\hline & & Q3 & 1.23 & $0.83,1.82$ & 0.3 \\
\hline & & Q2 & 0.99 & $0.66,1.49$ & 0.9 \\
\hline & & Q1 & 1.00 & & \\
\hline \multirow[t]{8}{*}{ Zung score } & \multirow[t]{4}{*}{ Basic } & Q4 & 1.71 & $1.17,2.50$ & 0.006 \\
\hline & & Q3 & 1.20 & $0.81,1.77$ & 0.4 \\
\hline & & Q2 & 1.14 & $0.79,1.65$ & 0.5 \\
\hline & & Q1 & 1.00 & & \\
\hline & \multirow[t]{4}{*}{ Extended } & Q4 & 1.43 & $0.99,2.50$ & 0.1 \\
\hline & & Q3 & 0.99 & $0.66,1.52$ & 0.9 \\
\hline & & Q2 & 1.05 & $0.71,1.54$ & 0.8 \\
\hline & & Q1 & 1.00 & & \\
\hline \multirow{4}{*}{$\begin{array}{l}\text { Antidepressant } \\
\text { medication use }\end{array}$} & \multirow[t]{2}{*}{ Basic } & Yes & 2.31 & $1.51,3.54$ & $<0.001$ \\
\hline & & No & 1.00 & & \\
\hline & \multirow[t]{2}{*}{ Extended } & Yes & 2.22 & $1.42,3.48$ & $<0.001$ \\
\hline & & No & 1.00 & & \\
\hline
\end{tabular}

CES-D Center for Epidemiologic Studies Depression Scale, Cl confidence interval, MetS metabolic syndrome, $O R$ odds ratio

aBasic: adjusted for age, education, sex, ethnicity; Extended: adjusted for set $1+$ smoking (cigarettes per day), physical activity (MET-minutes/day), CRP (mg/L)

${ }^{\text {b }}$ Quartile 1 (lowest quartile of scores) $=$ reference group

\section{Depressive symptoms, antidepressant medication and} individual MetS components

Those with the highest scores on both the CES-D and the Zung (highest quartiles) had a significantly increased likelihood of having low HDL-cholesterol (CES-D: OR: 1.89, $P<0.01$; Zung: OR: 1.48, $P<0.05$; basic model) (Table 3). The association between higher CES-D scores and risk for low HDL-cholesterol remained significant with addition of covariates, but was no longer significant for the Zung. Neither depressed mood measure was associated with any of the other individual MetS components.

Antidepressant use was significantly associated with higher odds for having elevated glucose levels, hypertension, and low HDL-cholesterol with full covariate adjustment (extended models, all $P<0.05$ ) (Table 4).

\section{Secondary analyses}

In a secondary set of analyses, neither of the age, sex or APOE $\varepsilon 4$ interaction terms added to the basic model were significant (all $P$ values $>0.4$, data not shown). Excluding participants with either CVD or diabetes did not change the pattern of results. Controlling for cognition (global composite score) in the extended model did not

Table 3 Odds of having individual metabolic syndrome components according to depressed mood in the Maine-Syracuse Longitudinal Study

\begin{tabular}{|c|c|c|c|c|c|}
\hline \multirow{2}{*}{$\begin{array}{l}\text { Depressive } \\
\text { symptoms }\end{array}$} & \multirow{2}{*}{$\begin{array}{l}\text { Covariate } \\
\text { set }^{\mathrm{a}}\end{array}$} & \multirow{2}{*}{$\begin{array}{l}\text { Quartile } \\
\text { of scores }\end{array}$} & \multicolumn{3}{|c|}{ MetS low HDL-cholesterol $^{c}$} \\
\hline & & & $\mathrm{OR}$ & $95 \% \mathrm{Cl}$ & $P$ \\
\hline \multirow[t]{8}{*}{ CES-D score } & Basic & Q4 & 1.89 & $1.30,2.74$ & 0.001 \\
\hline & & Q3 & 1.28 & $0.89,1.85$ & 0.2 \\
\hline & & Q2 & 1.41 & $0.98,2.04$ & 0.1 \\
\hline & & Q1 & 1.00 & & \\
\hline & Extended & Q4 & 1.67 & $1.13,2.46$ & 0.010 \\
\hline & & Q3 & 1.21 & $0.83,1.77$ & 0.3 \\
\hline & & Q2 & 1.34 & $0.91,1.98$ & 0.1 \\
\hline & & Q1 & 1.00 & & \\
\hline \multirow[t]{8}{*}{ Zung score } & Basic & Q4 & 1.48 & $1.02,2.14$ & 0.037 \\
\hline & & Q3 & 1.36 & $0.93,1.99$ & 0.1 \\
\hline & & Q2 & 1.01 & $0.71,1.44$ & 0.9 \\
\hline & & Q1 & 1.00 & & \\
\hline & Extended & Q4 & 1.30 & $0.88,1.91$ & 0.2 \\
\hline & & Q3 & 1.26 & $0.84,1.87$ & 0.3 \\
\hline & & Q2 & 0.99 & $0.69,1.44$ & 0.9 \\
\hline & & Q1 & 1.00 & & \\
\hline
\end{tabular}

CES-D Center for Epidemiologic Studies Depression Scale; $C$ confidence interval; MetS metabolic syndrome; $O R$ odds ratio

a Basic: adjusted for age, education, sex, ethnicity; Extended: adjusted for set $1+$ smoking (cigarettes per day), physical activity (MET-minutes/day), CRP (mg/L)

${ }^{\mathrm{b}}$ Quartile 1 (lowest quartile of scores) = reference group

${ }^{c}$ MetS clinical cut off points: reduced HDL-cholesterol: $<1.0 \mathrm{mmol} / \mathrm{L}$ or $<40 \mathrm{mg} / \mathrm{dL}$ for males; $<1.3 \mathrm{mmol} / \mathrm{L}$ or $<50 \mathrm{mg} / \mathrm{dL}$ for females [1] 
Table 4 Odds of having individual metabolic syndrome components according to use of antidepressant medications in the MaineSyracuse Longitudinal Study

\begin{tabular}{|c|c|c|c|c|c|c|c|c|c|c|c|}
\hline \multirow[t]{2}{*}{ Predictor } & \multirow[t]{2}{*}{ Covariate set $^{a}$} & \multirow[t]{2}{*}{ Group } & \multicolumn{3}{|c|}{ MetS elevated glucose ${ }^{b}$} & \multicolumn{3}{|c|}{ MetS hypertension ${ }^{b}$} & \multicolumn{3}{|c|}{ MetS low HDL-cholesterol ${ }^{b}$} \\
\hline & & & OR & $95 \% \mathrm{Cl}$ & $P$ & $\mathrm{OR}$ & $95 \% \mathrm{Cl}$ & $P$ & $\overline{\mathrm{OR}}$ & $95 \% \mathrm{Cl}$ & $P$ \\
\hline \multirow[t]{4}{*}{ Antidepressant medication use } & Basic & Yes & 2.01 & $1.30,3.13$ & 0.002 & 1.99 & $1.21,3.25$ & 0.006 & 1.66 & $1.10,2.51$ & 0.015 \\
\hline & & No & 1.00 & & & 1.00 & & & 1.00 & & \\
\hline & Extended & Yes & 1.95 & $1.23,3.09$ & 0.005 & 1.81 & $1.09,3.02$ & 0.023 & 1.57 & $1.03,2.40$ & 0.036 \\
\hline & & No & 1.00 & & & 1.00 & & & 1.00 & & \\
\hline
\end{tabular}

$\mathrm{Cl}$, confidence interval; MetS, metabolic syndrome; OR, odds ratio

abasic: adjusted for age, education, sex, ethnicity; Extended: adjusted for set $1+$ smoking (cigarettes per day), physical activity (MET-minutes/day), CRP (mg/L)

${ }^{b}$ MetS clinical cut off points: elevated fasting plasma glucose: $\geq 5.6 \mathrm{mmol} / \mathrm{L}$ or $\geq 100 \mathrm{mg} / \mathrm{dL}$; elevated blood pressure: systolic: $\geq 130$ and/or diastolic $\geq 85 \mathrm{mmHg}$; reduced HDL-cholesterol: $<1.0 \mathrm{mmol} / \mathrm{L}$ or $<40 \mathrm{mg} / \mathrm{dL}$ for males; $<1.3 \mathrm{mmol} / \mathrm{L}$ or $<50 \mathrm{mg} / \mathrm{dL}$ for females [1]

change the results. Finally, there was no attenuation of the results when body weight was added to the extended model testing the association between antidepressant use and MetS.

\section{Availability of data and materials}

The dataset supporting the conclusions of this article are available from the authors upon request.

\section{Discussion}

We have observed a significant association between elevated depressive symptoms and greater prevalence of MetS, controlling for socio-demographics, lifestyle factors and CRP. The findings were consistent across two different scales measuring the same construct (basic model). Few, if any, studies have examined relations between depressed mood using two different scales and this is necessary to the development of consistent operational definitions of depressed mood. Good cognitive studies, as an example, employ more than one index of a cognitive domain to define that domain. Our second major finding was that antidepressant use was associated with over 2-fold increased risk for MetS, adjusted for socio-demographics, lifestyle factors and CRP. Of the individual MetS components, low HDL-cholesterol was related to both measures of depressed mood, and antidepressant use was significantly related to elevated glucose levels, hypertension, and low HDL-cholesterol.

The results of the analyses indicate that the risk for MetS is not distributed equally across all quartiles of the depressed mood scale distribution. It was the individuals with depressed mood scores in the highest quartile that exhibited a significantly increased risk for MetS, compared to those individuals with scores in the lowest quartile. This makes sense from a clinical perspective as one would expect that the more extreme levels of depressed mood would be related to MetS. In the extended model, these statistically significant associations between the highest quartile of scores and MetS were attenuated but remained significant for the CES-D. This suggests that the presence of cardiovascular risk factors, such as inflammation, smoking or physical activity, attenuate the relations between depressed mood and MetS, and that this phenomenon is related to the fact that depressed mood raises the risk for CVD [8] and conversely the presence of CVD can lead to depression [39].

As a distinguishing factor from other studies, we were able to also assess if the results varied according to APOE $\varepsilon 4$ status. No difference was found between those with and without at least one allele. The study included participants across a wide age range. Age may impact upon one's cognitive abilities in relation to self-reported depressive symptoms. We found no evidence for an interaction between age and the depressive symptom measures. In addition, statistically controlling for cognitive function (adding the global composite score to the extended model) did not change the results.

Our findings are consistent with numerous other studies which have shown positive associations between depression and MetS. Pan et al [10] reviewed both cross-sectional studies, and prospective studies that reported odds ratios for depression as the outcome, and OR for MetS as the outcome. Depression and MetS were correlated in cross-sectional studies, and a bidirectional association was observed in the prospective studies. Multivariate logistic regression with depression as the dependent variable yielded an OR of 1.27 (95 \% CI 1.071.51) (based on 11 studies). Of note, this review included studies using both a self-reported symptom scale and diagnostic interview to assess depression. Interestingly, the association was slightly weaker when depression was assessed by diagnostic interview rather than self-reported $(\mathrm{OR}=1.29$ vs. 1.51) [10]. Data on antidepressant medication use was not examined in this review.

Our study examined depressive symptoms, assessed through the completion of self-rated scales, reliant upon the participant's perception of symptom burden. Other studies have demonstrated a similar pattern of association with clinically diagnosed depressive disorders established objectively using standardized diagnostic interviews. A number of studies have shown positive relations between major depressive disorder (both current and lifetime) and 
MetS [11-13]. For example, Butnoriene et al [11] showed a significant relation between major depressive disorder (both current and lifetime) and depressive symptoms with MetS prevalence in a community sample. Data from the National Health and Nutrition Examination Survey (NHANES III) obtained from young adults found that a history of major depression was associated with increased odds of MetS in women, but not in men [13]. Similarly, Goldbacher et al [40] showed that a lifetime history of major depression predicted an increased risk of developing MetS in middle-aged women.

We found that depressive symptoms may be directly associated with HDL-cholesterol levels. Other studies investigating depression in relation to the individual components of MetS have shown significant and independent associations between low HDL-cholesterol [20, 41], as well as large waist circumference [20, 41], hypertension [13], and high triglycerides [13, 20] with depression. In the present study, antidepressant use was associated with higher glucose and blood pressure levels, and lower HDL-cholesterol. Use of antidepressant medication has been previously associated with higher triglycerides, systolic BP, and waist circumference [20]. Weight gain during antidepressant treatment can be either a sign of improvement in patients who have weight loss as a symptom of depression, or may be a residual symptom of weight gain from overeating when depressed [18]. Substantial weight gain during the early phase of treatment with antidepressants or weight gain that continues despite the resolution of depressive symptoms may be a sideeffect of the drug treatment [18]. A review by Newcomer and Haupt [42] indeed concluded that antipsychotic medications may be associated with adverse metabolic effects, including weight gain and decreases in insulin sensitivity, which may further contribute to increasing plasma glucose and lipid levels, and therefore MetS risk.

\section{Mechanisms}

There are a number of potential mechanisms that may underlie the association between depressed mood and MetS. Firstly, depression has been associated with obesity [43], inflammation [44], and insulin resistance [45], which are all linked with MetS. Inflammation as a consequence of obesity is likely to be a central component $[41,46]$. Depression may facilitate physiological changes, such as dysregulation of the hypothalamus-pituitary-adrenal (HPA) axis, resulting in increased secretion of corticotrophinreleasing hormone, adrenocorticotropic hormone, and cortisol [47]. This promotes deposition of visceral fat tissue, which secretes inflammatory cytokines implicated in insulin resistance, a key factor in MetS. Cortisol also inhibits lipid mobilization, directly effecting dyslipidemia $[14,41]$.

Alternatively, depressed mood may result in increased consumption of food and/or alcohol as a means for coping with negative emotion, promoting weight gain and subsequently activating an inflammatory response [12]. Other negative, depression-related behaviours, such as the consumption of an unhealthy diet, engaging in little physical activity and poor sleep patterns may enhance oxidative stress, adiposity, inflammation, and an increased risk for metabolic disturbances [12, 48, 49].

\section{Implications}

Individuals with elevated depressive symptoms, even without major depressive disorder, and individuals taking antidepressant medication should be considered at risk for MetS. Assessment and monitoring of MetS components should be routine care for these people [50]. Lifestyle changes could be recommended if patients are found to be at increased risk for cardiometabolic risk factors. The use of self-reported depression symptom scales are therefore clinically important for identifying individuals at risk for more severe depression and metabolic sequela. Contrary to a few studies and consistent with others we find no relation higher risk for MetS in persons carrying one or two APOE $\varepsilon 4$ alleles.

\section{Limitations}

Due to the cross-sectional design, we are only able to infer an association between elevated depressive symptoms, antidepressant use, and higher MetS prevalence. No inferences regarding causality can be made. The results may not be generalizable to the African American community as they only comprised a small proportion of the sample $(7.5 \%)$. Finally, not all possible relevant lifestyle behaviors or social psychological variables were included in the study. Other inflammatory markers, such as leptin and adiponectin were not measured. We also did not have data on family history of depression or disease, which may have an effect on our findings, but was not a question raised in this study. Absence of data on duration of treatment with antidepressant medications is a limitation, albeit our major outcomes for inferring depression (more specifically depressed mood) were the two depressed mood scales.

\section{Strengths}

The major strengths of the study include the representative, community-based sample of men and women, the assessment of MetS criteria, depressive symptoms, cardiovascular risk varibles and other health and lifestyle factors, and the fact that examiners were blind to the subject's MetS status.

\section{Conclusions}

Depressive symptoms are associated with an increased prevalence of MetS. Those taking antidepressants have over twice the likelihood of having MetS, compared with 
those not taking such medication. Well-designed longitudinal studies are required to examine the chronological sequence of the development of depression and MetS. More studies are also needed to examine the biological and behavioral mechanisms underlying this depression-MetS relation, important for the prevention and management of both.

\section{Abbreviations}

APOE $\varepsilon 4$, apolipoprotein $\varepsilon 4$; BMI, body mass index; BP, blood pressure; CES-D, Center for Epidemiological Studies Depression Scale; Cl, confidence interval; CRP,C-reactive protein; CVD, Cardiovascular disease; HDL, Highdensity lipoprotein; LDL, Low-density lipoprotein; MET, metabolic equivalent; MetS, Metabolic Syndrome; MSLS, Maine-Syracuse Longitudinal Study; OR, odds ratio; TC, total cholesterol

\section{Acknowledgements}

The authors greatly appreciate the study participants and those who assisted with data collection. This study was supported in part by National Heart, Lung, and Blood Institute (grant numbers R01HL67358, R01HL81290); by the National Institute on Aging (grant R01AG03055). GEC was supported by a Sidney Sax Research Fellowship (National Health and Medical Research Council, Australia, grant number APP1054567).

\section{Availability of data and materials}

Data may be made available by contacting the authors.

\section{Authors' contributions}

MFE and MAR were responsible for the development and data collection of the MSLS. GEC and MFE conceived this particular study within the MSLS. GEC analyzed the data and wrote the manuscript. MFE was involved in critical review of the manuscript and some writing. MR critically reviewed the manuscript. All authors have read and approved the final manuscript.

\section{Competing interests}

The authors declare that they have no competing interests.

\section{Consent for publication}

Not applicable.

\section{Ethics approval and consent to participate}

This study was approved by the University of Maine Institutional Review Board. Written informed consent was obtained from all subjects.

\section{Author details}

'Alliance for Research in Exercise, Nutrition and Activity (ARENA), Sansom Institute for Health Research, University of South Australia, GPO Box 2471, Adelaide, South Australia 5001, Australia. ${ }^{2}$ Department of Psychology, University of Maine, Orono, ME, USA. ${ }^{3}$ Graduate School of Biomedical Sciences and Engineering, University of Maine, Orono, ME, USA.

\section{Received: 23 February 2016 Accepted: 29 May 2016}

\section{Published online: 10 June 2016}

\section{References}

1. Alberti KG, Eckel RH, Grundy SM, Zimmet PZ, Cleeman JI, Donato KA, et al. Harmonizing the metabolic syndrome: a joint interim statement of the International Diabetes Federation Task Force on Epidemiology and Prevention; National Heart, Lung, and Blood Institute; American Heart Association; World Heart Federation; International Atherosclerosis Society; and International Association for the Study of Obesity. Circulation. 2009;120:1640-5.

2. Alberti KG, Zimmet P, Shaw J. Metabolic syndrome - a new world-wide definition. A Consensus Statement from the International Diabetes Federation. Diabet Med. 2006;23:469-80.

3. Galassi A, Reynolds K, He J. Metabolic syndrome and risk of cardiovascular disease: a meta-analysis. Am J Med. 2006;1 19:812-9.

4. Wilson PW, D'Agostino RB, Parise H, Sullivan L, Meigs JB. Metabolic syndrome as a precursor of cardiovascular disease and type 2 diabetes mellitus. Circulation. 2005;112:3066-72.
5. Arnolov J, Ingelsson E, Sundstrom J, Lind L. Impact of body mass index and the metabolic syndrome on the risk of cardiovascular disease and death in middle-aged men. Circulation. 2010;121:230-U88.

6. Ho JS, Cannaday JJ, Barlow CE, Mitchell TL, Cooper KH, FitzGerald SJ. Relation of the number of metabolic syndrome risk factors with all-cause and cardiovascular mortality. Am J Cardiol. 2008;102:689-92.

7. Mezuk B, Eaton WW, Albrecht S, Golden SH. Depression and type 2 diabetes over the lifespan: a meta-analysis. Diabetes Care. 2008;31:2383-90.

8. Cohen BE, Edmondson D, Kronish IM. State of the Art Review: Depression, Stress, Anxiety, and Cardiovascular Disease. Am J Hypertens. 2015;28:1295-302.

9. National Institute of Mental Health. Major Depression Among Adults. http://www.nimh.nih.gov/health/statistics/prevalence/major-depressionamong-adults.shtml. Accessed 30 Nov 2015.

10. Pan A, Keum N, Okereke Ol, Sun Q, Kivimaki M, Rubin RR, et al. Bidirectional association between depression and metabolic syndrome: a systematic review and meta-analysis of epidemiological studies. Diabetes Care. 2012;35:1171-80.

11. Butnoriene J, Bunevicius A, Norkus A, Bunevicius R. Depression but not anxiety is associated with metabolic syndrome in primary care based community sample. Psychoneuroendocrinology. 2014;40:269-76.

12. Goldbacher EM, Matthews KA. Are psychological characteristics related to risk of the metabolic syndrome? A review of the literature. Ann Behav Med. 2007;34:240-52

13. Kinder LS, Carnethon MR, Palaniappan LP, King AC, Fortmann SP. Depression and the metabolic syndrome in young adults: findings from the Third National Health and Nutrition Examination Survey. Psychosom Med. 2004;66:316-22

14. Lin KP, Liang TL, Liao IC, Tsay SL. Associations among depression, obesity, and metabolic syndrome in young adult females. Biol Res Nurs. 2014;16:327-34.

15. Ribeiro RP, Marziale MH, Martins JT, Ribeiro PH, Robazzi ML, Dalmas JC. Prevalence of Metabolic Syndrome among nursing personnel and its association with occupational stress, anxiety and depression. Rev Lat Am Enfermagem. 2015;23:435-40.

16. Rubin RR, Ma Y, Marrero DG, Peyrot M, Barrett-Connor EL, Kahn SE, et al. Elevated depression symptoms, antidepressant medicine use, and risk of developing diabetes during the diabetes prevention program. Diabetes Care. 2008:31:420-6.

17. Blumenthal SR, Castro VM, Clements CC, Rosenfield HR, Murphy SN, Fava M, et al. An electronic health records study of long-term weight gain following antidepressant use. JAMA Psychiatry. 2014;71:889-96.

18. Fava M. Weight gain and antidepressants. J Clin Psychiatry. 2000;61 Suppl 11:37-41.

19. Mclntyre RS, Park KY, Law CW, Sultan F, Adams A, Lourenco MT, et al. The association between conventional antidepressants and the metabolic syndrome: a review of the evidence and clinical implications. CNS Drugs. 2010;24:741-53.

20. Pyykkonen AJ, Raikkonen K, Tuomi T, Eriksson JG, Groop L, Isomaa B. Association between depressive symptoms and metabolic syndrome is not explained by antidepressant medication: results from the PPP-Botnia Study. Ann Med. 2012;44:279-88.

21. Elias MF, Robbins MA, Budge MM, Elias PK, Brennan SL, Johnston C, et al. Homocysteine, folate, and vitamins B6 and B12 blood levels in relation to cognitive performance: the Maine-Syracuse study. Psychosom Med. 2006;68:547-54.

22. Robbins MA, Elias MF, Elias PK, Budge MM. Blood pressure and cognitive function in an African-American and a Caucasian-American sample: the Maine-Syracuse Study. Psychosom Med. 2005;67:707-14.

23. Dore GA, Elias MF, Robbins MA, Budge MM, Elias PK. Relation between central adiposity and cognitive function in the Maine-Syracuse Study: attenuation by physical activity. Ann Behav Med. 2008;35:341-50.

24. Elias MF, Robbins MA, Budge MM, Abhayaratna WP, Dore GA, Elias PK. Arterial pulse wave velocity and cognition with advancing age. Hypertension. 2009;53:668-73.

25. McKhann G, Drachman D, Folstein M, Katzman R, Price D, Stadlan EM Clinical diagnosis of Alzheimer's disease: report of the NINCDS-ADRDA Work Group under the auspices of Department of Health and Human Services Task Force on Alzheimer's Disease. Neurology. 1984;34:939-44.

26. World Health Organization. The ICD 10 classification of mental and behavioral disorders: clinical descriptions and diagnostic guidelines. Geneva: World Health Organization; 1992

27. Radloff LS. The CES-D Scale: a self-report depression scale for research in the general population. Appl Psychol Meas. 1977;1:385-401.

28. Zung WW. A Self-Rating Depression Scale. Arch Gen Psychiatry. 1965;12:63-70. 
29. Gabrys JB, Peters K. Reliability, discriminant and predictive validity of the Zung Self-rating Depression Scale. Psychol Rep. 1985;57:1091-6.

30. Knight RG, Waal-Manning HJ, Spears GF. Some norms and reliability data for the State-Trait Anxiety Inventory and the Zung Self-Rating Depression scale. Br J Clin Psychol. 1983;22(Pt 4):245-9.

31. Knight RG, Williams S, McGee R, Olaman S. Psychometric properties of the Centre for Epidemiologic Studies Depression Scale (CES-D) in a sample of women in middle life. Behav Res Ther. 1997;35:373-80.

32. Roberts RE. Reliability of the CES-D Scale in different ethnic contexts. Psychiatry Res. 1980;2:125-34.

33. Kaaks $R$, Riboli E. Validation and calibration of dietary intake measurements in the EPIC project: methodological considerations. European Prospective Investigation into Cancer and Nutrition. Int J Epidemiol. 1997;26 suppl 1:S15-25.

34. Riboli E, The KR, EPIC. Project: rationale and study design. European Prospective Investigation into Cancer and Nutrition. Int J Epidemiol. 1997:26 suppl 1:S6-14.

35. Wolf AM, Hunter DJ, Colditz GA, Manson JE, Stampfer MJ, Corsano KA, et al. Reproducibility and validity of a self-administered physical-activity quesionnaire. Int J Epidemiol. 1994;23:991-9.

36. Ainsworth BE, Haskell WL, Leon AS, Jacobs Jr DR, Montoye HJ, Sallis JF, et al. Compendium of physical activities: classification of energy costs of human physical activities. Med Sci Sports Exerc. 1993;25:71-80.

37. Kroke A, Klipstein-Grobusch K, Voss S, Moseneder J, Thielecke F, Noack R et al. Validation of a self-administered food-frequency questionnaire administered in the European Prospective Investigation into Cancer and Nutrition (EPIC) Study: comparison of energy, protein, and macronutuient intakes estimated with the doubly labeled water, urinary nitrogen, and repeated 24-h dietary recall methods. Am J Clin Nutr. 1999;70:439-47.

38. Corsentino EA, Sawyer K, Sachs-Ericsson N, Blazer DG. Depressive symptoms moderate the influence of the apolipoproteine epsilon4 allele on cognitive decline in a sample of community dwelling older adults. Am J Geriatr Psychiatry. 2009;17:155-65.

39. Almas A, Forsell $Y$, lqbal R, Janszky I, Moller J. Severity of Depression. Anxious Distress and the Risk of Cardiovascular Disease in a Swedish Population-Based Cohort. PLoS One. 2015;10:e0140742.

40. Goldbacher EM, Bromberger J, Matthews KA. Lifetime history of major depression predicts the development of the metabolic syndrome in middle-aged women. Psychosom Med. 2009;71:266-72.

41. Dunbar JA, Reddy P, Davis-Lameloise N, Philpot B, Laatikainen T, Kilkkinen A, et al. Depression: an important comorbidity with metabolic syndrome in a general population. Diabetes Care. 2008;31:2368-73.

42. Newcomer JW, Haupt DW. The metabolic effects of antipsychotic medications. Can J Psychiatry. 2006;51:480-91.

43. Luppino FS, de Wit LM, Bouvy PF, Stijnen T, Cuijpers P, Penninx BW, et al. Overweight, obesity, and depression: a systematic review and meta-analysis of longitudinal studies. Arch Gen Psychiatry. 2010;67:220-9.

44. Howren MB, Lamkin DM, Suls J. Associations of depression with C-reactive protein, IL-1, and IL-6: a meta-analysis. Psychosom Med. 2009;71:171-86.

45. Austin AW, Gordon JL, Lavoie KL, Arsenault A, Dasgupta K, Bacon SL. Differential association of insulin resistance with cognitive and somatic symptoms of depression. Diabet Med. 2014;31:994-1000.

46. Rethorst CD, Bernstein I, Trivedi MH. Inflammation, obesity, and metabolic syndrome in depression: analysis of the 2009-2010 National Health and Nutrition Examination Survey (NHANES). J Clin Psychiatry. 2014;75:e1428-32.

47. Bjorntorp $\mathrm{P}$, Rosmond R. The metabolic syndrome-a neuroendocrine disorder? Br J Nutr. 2000;83 Suppl 1:S49-57.

48. Skalicky J, Muzakova V, Kandar R, Meloun M, Rousar T, Palicka V. Evaluation of oxidative stress and inflammation in obese adults with metabolic syndrome. Clin Chem Lab Med. 2008;46:499-505.

49. Strine TW, Mokdad AH, Dube SR, Balluz LS, Gonzalez O, Berry JT, et al. The association of depression and anxiety with obesity and unhealthy behaviors among community-dwelling US adults. Gen Hosp Psychiatry. 2008;30:127-37.

50. McIntyre RS, Rosenbluth M, Ramasubbu R, Bond DJ, Taylor VH, Beaulieu S, et al. Managing medical and psychiatric comorbidity in individuals with major depressive disorder and bipolar disorder. Ann Clin Psychiatry. 2012;24:163-9.

\section{Submit your next manuscript to BioMed Central and we will help you at every step:}

- We accept pre-submission inquiries

- Our selector tool helps you to find the most relevant journal

- We provide round the clock customer support

- Convenient online submission

- Thorough peer review

- Inclusion in PubMed and all major indexing services

- Maximum visibility for your research

Submit your manuscript at www.biomedcentral.com/submit
() BioMed Central 